Shoichi Tani • Masafumi Taniwaki • Yoshihito Taniguchi

Shigeru Minoguchi • Kazuki Kuroda • Hua Han

Tomokazu Aoki - Shin-ichi Miyatake • Nobuo Hashimoto

Tasuku Honjo

\title{
Chromosomal mapping of two RBP-J-related genes: Kyo-T and RBP-L
}

\begin{abstract}
We have recently isolated two genes encoding proteins which have either homology or affinity to RBP-J, a transcription factor involved in Notch signaling. Kyo-T interacts with RBP-J and possibly regulates the function of RBP-J. RBP-L has a highly homologous region with RBP$\mathrm{J}$ but the function of RBP-L is unknown. Fluorescence in situ hybridization analysis of human metaphase chromosomes localized Kyo-T and $R B P-L$ to Xq26 and 20q12-13.1, respectively.
\end{abstract}

Key words Chromosomal mapping $\cdot$ Kyo-T $\cdot$ RBP-L RBP-J

\section{Introduction}

RBP-J is a transcription factor recognizing a consensus sequence $(\mathrm{C} / \mathrm{T})$ GTGGGAA and is involved in cell fate determination of various cell lineages (Furukawa et al. 1992; Honjo 1996). The structure of RBP-J is strongly conserved during evolution and we have reported that RBP-J is the key protein to mediate signaling from Notch, a neurogenic transmembrane-type protein, to the nucleus in a unique manner to control the expression of the target proteins responsible for cell fate decisions (reviewed in Honjo 1996). To understand the regulatory mechanism of RBP-J, we identified two proteins physically associating with the RBP$\mathrm{J}$ protein using yeast two-hybrid screening: RAM23, a part

S. Tani · Y. Taniguchi $\cdot$ S. Minoguchi $\cdot$ K. Kuroda $\cdot$ H. Han ·

T. Honjo $(\bowtie)$

Department of Medical Chemistry, Faculty of Medicine,

Kyoto University, Sakyo-ku, Kyoto 606, Japan

Tel. +81-75-753-4371; Fax +81-75-753-4388

e-mail: honjo@mfour.med.kyoto-u.ac.jp

S. Tani $\cdot$ T. Aoki $\cdot$ S. Miyatake $\cdot$ N. Hashimoto

Department of Neurosurgery, Faculty of Medicine,

Kyoto University, Kyoto, Japan

M. Taniwaki

The Third Department of Internal Medicine, Kyoto Prefectural

Medical School, Kyoto, Japan of the Notch protein (Tamura et al. 1995), and Kyo-T, a LIM-only protein (Taniguchi et al. 1998). RBP-L is a homologous protein to RBP-J and has a consensus sequence with RBP-J. RBP-L may or may not be involved in Notch signaling (Minoguchi et al. 1997).

Since Notch signaling has been reported to participate throughout all stages of embryogenesis, including neurogenesis, somatogenesis, oogenesis, and hematopoiesis, the complete loss-of-function mutations of Notch, RBP-J, and related genes cause embryonic lethality (Swiatek et al. 1994; Conlon et al. 1995; Oka et al. 1995). The point mutations of Notch and its ligand in man cause unique diseases like cevebral autosomal dominant arteriopathy with subcortical infarcts and leukoencephalopathy (CADASIL) (Joutel et al. 1996) and Alagille syndromes (Li et al. 1997; Oda et al. 1997). Therefore, it is important to determine chromosomal locations of the new genes which are associated with or related to the Notch/RBP-J signaling pathway.

\section{Results and discussion}

As a first step, we generated a genomic DNA probe for fluorescence in situ hybridization (FISH) analysis by screening a human placenta genomic DNA library in the EMBL3 SP6/T7 phage vector (Clontech, Palo Alto, CA, USA). Using human Kyo-T cDNA as a probe (Taniguchi et al. 1998), we isolated a human genomic clone and partially sequenced this clone to confirm it as the human counterpart of the Kyo-T gene. Exons 3 and 4 of this clone have sequences which are identical to those of mouse Kyo-T cDNA. These regions are separated by a putative intron with the $5^{\prime}$ splice donor (GTATGC) and the $3^{\prime}$ splice acceptor (GTCTAG) sites. In the case of RBP-L, we first confirmed the availability of mouse RBP-L cDNA for detection of a human counterpart by Southern blotting (data not shown) and used this mouse RBP-L cDNA for the isolation of a human genomic clone from the same library as Kyo-T. Partial sequences of this clone showed that it contained exons 10,11 , and 12 that are more than $75 \%$ homologous to 
Fig. 1 Chromosomal localization of the human Kyo-T and RBP$L$ genes by fluorescene in situ hybridization. Fluorescein isothiocyanate signals are indicated with arrows in a and chromosomes of the same metaphase were counterstained to obtain a 4',6-diamidino-2-phenylindole banding pattern b. Marked signals of $K y o-T$ and $R B P-L$ were detected at Xq26 and 20q12-13.1, respectively
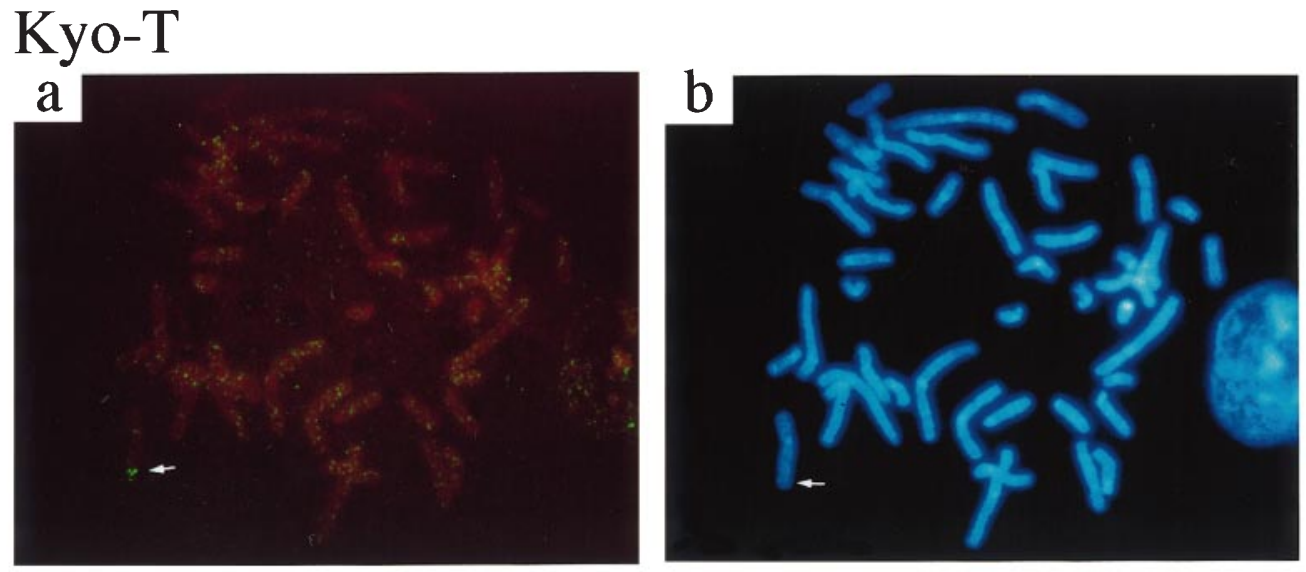

\section{RBP-L}
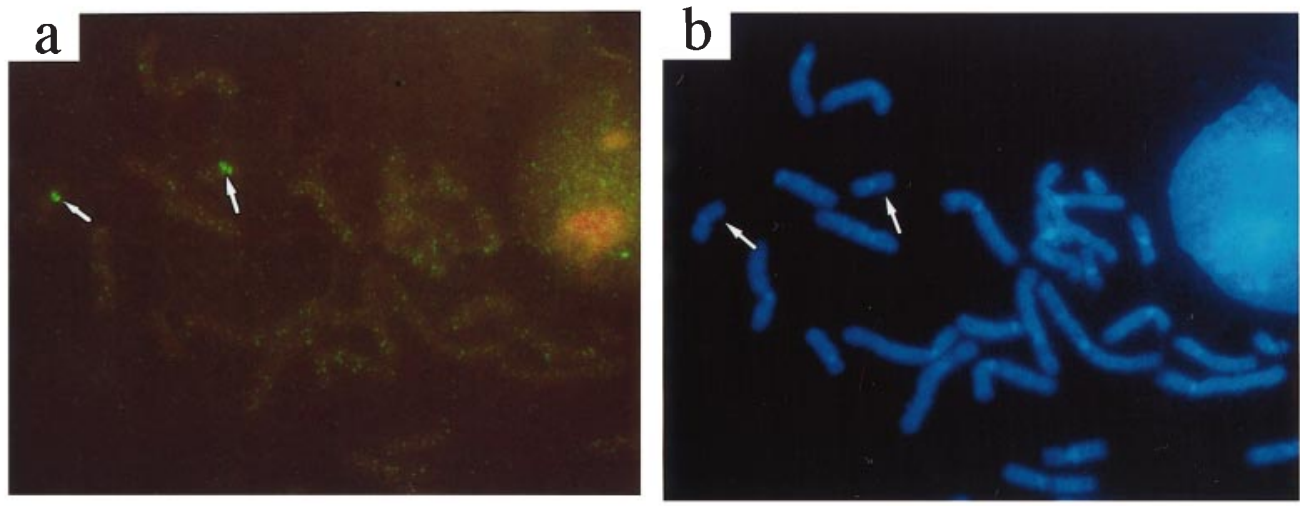

the corresponding mouse RBP-L exons, and are separated by typical splice donor and acceptor sequences. In both $K y o-T$ and $R B P-L$, there were no pseudogene bands detected by Southern hybridization. All the bands detected by hybridization with the probes used are explained by the genomic clones isolated.

Chromosomal in situ hybridization of these two genes, $K y o-T$ and $R B P-L$, was carried out using the isolated phage DNA clones labeled with biotin-11-dUTP by nicktranslation. Chromosome spreading and hybridization were carried out as described previously (Taniwaki et al. 1994). Kyo-T was mapped on Xq26 in 25 out of 25 metaphase cells as shown in Fig. 1. Three diseases causing mental retardation, i.e., Cowchock syndrome, Pettigrew syndrome, and Gustavson syndrome, are associated with genes on Xq25. In addition, Bazex syndrome, congenital generalized hypertrichosis, thoracoabdominal syndrome, albinismdeafness syndrome, split hand/foot malformation type 2, Borjeson-Forssman-Lehmann syndrome, X-linked hypoparathyroidism, and $\mathrm{X}$-linked immunoneurologic syndrome are associated with genes on $\mathrm{Xq} 26$. $R B P-L$ was mapped on 20q12-13.1 in 28 out of 28 metaphase cells (Fig. 1 ), in which the gene for maturity-onset diabetes of the young type 1 is reported to be located. However, this disease is believed to be caused by mutations of transcription factor 14 or hepatic nuclear factor (HNF4) (Yamagata et al. 1996). Since Notch signaling plays essential roles in neu- rogenesis, it is important to investigate the role of RBP-Jrelated genes in the diseases mentioned above as well as other diseases presumably caused by interference in neurogenesis.

Acknowledgements We thank Ms. T. Tanaka for preparation of the manuscript. This work was supported by grants from the Ministry of Education, Science, Sports and Culture of Japan.

\section{References}

Conlon RA, Reaume AG, Rossant J (1995) Notch1 is required for the coordinate segmentation of somites. Development 121: 1533-1545

Furukawa T, Maruyama S, Kawaichi M, Honjo T (1992) The Drosophila homolog of the immunoglobulin recombination signal-binding protein regulates peripheral nervous system development. Cell 69: $1191-1197$

Honjo T (1996) The shortest path from the surface to the nucleus: RBP-J kappa/Su(H) transcription factor. Genes Cells 1: 1-9

Joutel A, Corpechot C, Ducros A, Vahedi K, Chabriat H, Mouton P, Alamowitch S, Domenga V, Cecillion M, Marechal E, Maciazek J, Vayssiere C, Cruaud C, Cabanis EA, Ruchoux MM, Weissenbach J, Bach JF, Bousser MG, Tournier Lasserve E (1996) Notch3 mutations in CADASIL, a hereditary adult-onset condition causing stroke and dementia. Nature 383: 707-710

Li L, Krantz ID, Genin A, Banta AB, Collins CC, Qi M, Trask BJ, Kuo WL, Cochran J, Costa T, Pierpont ME, Rand EB, Piccoli DA, Hood L, Spinner NB (1997) Alagille syndrome is caused by mutations in human Jagged1, which encodes a ligand for Notch. Nature Genet 16: $243-250$ 
Minoguchi S, Taniguchi Y, Kato H, Okazaki T, Strobl LJ, Zimber Strobl U, Bornkamm GW, Honjo T (1997) RBP-L, a transcription factor related to RBP-Jkappa. Mol Cell Biol 17: 26792687

Oda T, Elkahloun AG, Pike BL, Okajima K, Krantz ID, Genin A, Piccoli DA, Meltzer PS, Spinner NB, Collins FS, Chandrasekharappa SC (1997) Mutations in the human Jagged1 gene are responsible for Alagille syndrome. Nature Genet 16: 235242

Oka C, Nakano T, Wakeham A, de la Pompa JL, Mori C, Sakai T, Okazaki S, Kawaichi M, Shiota K, Mak TW, Honjo T (1995) Disruption of the mouse RBP-J kappa gene results in early embryonic death. Development 121: 3291-3301

Swiatek PJ, Lindsell CE, del Amo FF, Weinmaster G, Gridley T (1994) Notch1 is essential for postimplantation development in mice. Genes Dev 8: 707-719
Tamura K, Taniguchi Y, Minoguchi S, Sakai T, Tun T, Furukawa T, Honjo T (1995) Physical interaction between a novel domain of the receptor Notch and the transcription factor RBP-J kappa/Su(H). Curr Biol 5: 1416-1423

Taniguchi Y, Furukawa T, Tun T, Han H, Honjo T (1998) LIM protein KyoT2 negatively regulates transcription by association with the RBP-J DNA-binding protein. Mol Cell Biol 18: 644-654

Taniwaki M, Matsuda F, Jauch A, Nishida K, Takashima T, Tagawa S, Sugiyama H, Misawa S, Abe T, Kashima K (1994) Detection of $14 \mathrm{q} 32$ translocations in B-cell malignancies by in situ hybridization with yeast artificial chromosome clones containing the human $\operatorname{IgH}$ gene locus. Blood 83: 2962-2969

Yamagata K, Furuta H, Oda N, Kaisaki PJ, Menzel S, Cox NJ, Fajans SS, Signorini S, Stoffel M, Bell GI (1996) Mutations in the hepatocyte nuclear factor-4alpha gene in maturity-onset diabetes of the young (MODY1). Nature 384: 458-460 